\title{
Seismic Behavior of Steel Reinforced Concrete Beam-Columns and Frames
}

\author{
Mark D. Denavit ${ }^{1}$, Jerome F. Hajjar ${ }^{2}$, and Roberto T. Leon ${ }^{3}$ \\ ${ }^{1}$ Graduate Research Assistant, Department of Civil and Environmental Engineering, \\ University of Illinois at Urbana-Champaign, Urbana, IL 61801-2352. \\ 2 Professor and Chair, Department of Civil and Environmental Engineering, \\ Northeastern University, Boston, MA 02115. \\ ${ }^{3}$ Professor, School of Civil and Environmental Engineering, Georgia Institute of \\ Technology, Atlanta, GA 30332.
}

\section{ABSTRACT}

The ability to perform accurate nonlinear simulations is a key component in the assessment of the behavior of seismic force resisting systems. A three-dimensional distributed plasticity formulation for composite beam-columns suitable for nonlinear static and dynamic analyses of composite seismic force resisting systems has been developed. New uniaxial constitutive relations are developed for the concrete and steel elements to simulate the cyclic response of steel reinforced concrete (SRC) members. The relations account for the salient features of each material, as well as the interaction between the two, including for concrete: varying levels of confinement within a section, cracking, crushing, and spalling, and for steel: cyclic plasticity and residual stresses. The accuracy of the formulation is validated against a comprehensive set of results from monotonically and cyclically loaded beam-column specimens. The formulation is suitable for use in parametric studies to quantify the seismic performance factors of special moment frames using steel reinforced concrete columns and structural steel beams following recommendations of the recently released FEMA P695 report.

\section{INTRODUCTION}

Steel-concrete composite columns have been shown to have high strength, stiffness, and ductility. However, there is a lack of quantitatively justified guidance for design of structures with these members. Notably, there is little data is available to justify the structural system response factors (e.g., $R, C_{d}$, and $\Omega_{o}$ ) given in the specifications. In the current work, we strive to fill these gaps through developing system response factors; assessing beam-column strength; and establishing guidelines for the computation of equivalent composite beam-column rigidity to be used in seismic analysis and design of composite frames. Accurate nonlinear static and dynamic computational formulations are required to achieve these goals. Specifically, for developing rational system response factors, a model should directly simulate all predominate inelastic effects from the onset of yielding through strength and stiffness degradation causing collapse, while being sufficiently robust to track inelastic force redistribution without convergence problems up to the point of collapse (FEMA 2009). 
Often, SRC members are modeled with constitutive relations taken directly from structural steel and reinforced concrete theory. This approach neglects the beneficial effects that the composite section provides, namely the added confinement of the concrete by the steel shape and the delay of local buckling in steel shape (although local buckling is often not modeled in structural steel). Several researchers have developed models specifically for use with SRC members (Mirza 1989, Sanz Picon 1992, Elnashai and Elghazouli 1993, El-Tawil and Deierlein 1999, Chen and Lin 2006) that do account for the beneficial effects provided by the composite section. A defining feature among all of these models is the varying levels of concrete confinement assumed throughout the cross-section. The differences between the models arise from the use of different mechanistic assumptions and empirical relations for the various aspects of section behavior (e.g., differences in determination of confining pressure and confinement model). The validity the models and thus their underlying assumptions are shown through comparisons between computation and experimental results. The model presented in this work utilizes a sophisticated finite element as well as comprehensive cyclic constitutive relations. Additionally, extensive validation is performed to ensure accuracy.

\section{THREE-DIMENSIONAL MIXED BEAM FINITE ELEMENT}

Frame analyses using distributed-plasticity beam-column elements strike a favorable balance of computational efficiency and accuracy. Additionally, mixed formulations (defined here as treating both element displacements and stress resultants as primary state variables) provide more accurate results with fewer elements as compared to either displacement- or force-based formulations (Alemdar and White 2005). Tort and Hajjar (2010) developed a three-dimensional mixed beam-column element for the analysis of composite frames that include rectangular concrete-filled steel tube members, validating against a large number of experimental tests of composite members and frames. This finite element was adapted and further validated against an additional set of experimental tests on circular concrete-filled steel tube members (Denavit 2009). The element stiffness and internal force are derived in the corotational frame using small strain assumptions. When accompanied with an exact transformation between the corotational and global frame the element is capable of capturing moderate deformation and rotation behavior. The use of independent force interpolation functions provides for a more accurate representation of the nonlinear curvature along the length of a yielded member. Implemented within the OpenSees framework (OpenSees 2011), the element can be used with the wide variety of other elements and solution algorithms available in the framework.

\section{UNIAXIAL CYCLIC CONSTITUTIVE RELATIONS}

The formulation relies on accurate constitutive relations to achieve accurate results. The constitutive relations are defined for the finite element at the section level using a fiber model. A fiber model allows the wide variety of behavior exhibited by SRC sections to be described by the integration of uniaxial constitutive relations located throughout the section.

It is desired that the fiber section be defined with minimal input from the analyst. The required input from the analyst includes: basic dimensions (depth of the composite 
section, $H$ and width of the composite section, $B$ ), dimensions of the steel section (depth, $d$, flange width, $b_{f}$, flange thickness, $t_{f}$, and web thickness, $t_{w}$ ), material properties of steel section (yield strength, $F_{y s}$, ultimate strength, $F_{u s}$, and elastic modulus, $E_{s}$ ), concrete material properties (compressive strength, $f_{c}^{\prime}$ ), dimensions and material properties of the longitudinal and transverse reinforcement, and fiber density. Using these parameters, the uniaxial constitutive relations and fiber section are defined. Five distinct regions are identified within the section (Figure 1). Separate constitutive relations are defined for each of these regions.

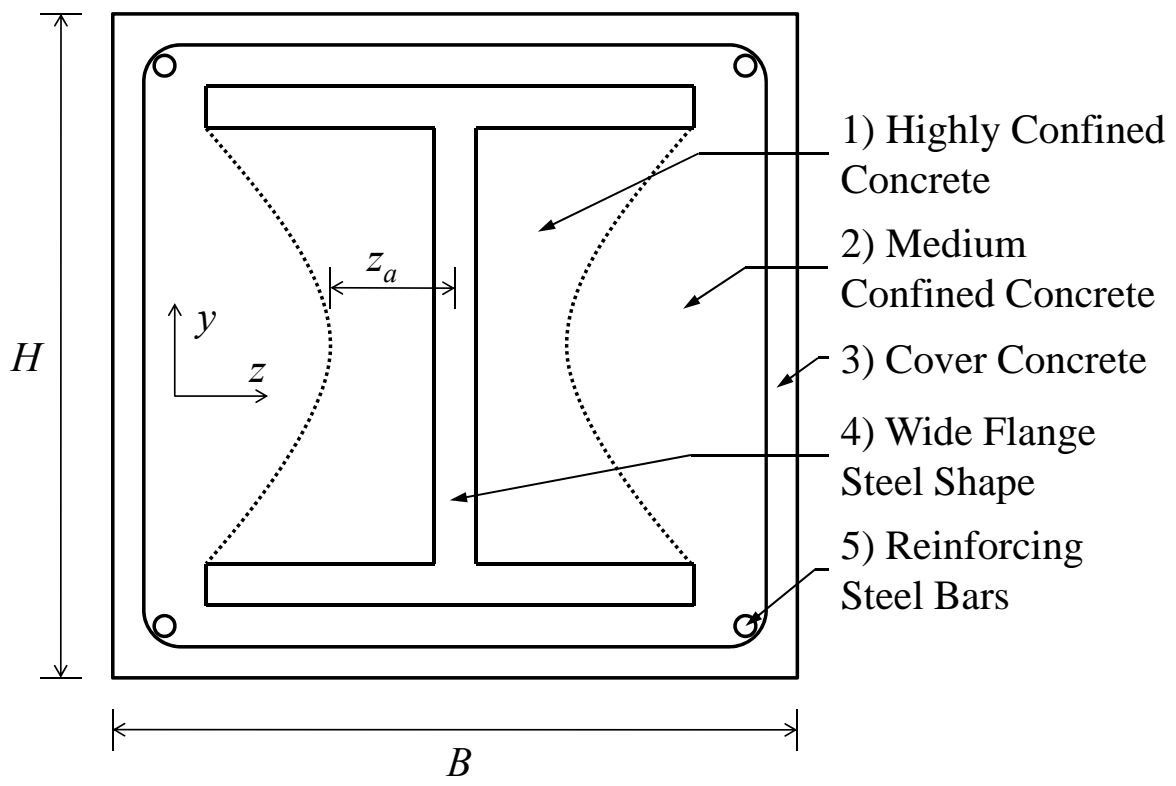

Figure 1. SRC Section

The constitutive relation used for the wide flange steel shape and the reinforcing steel bars is based on the bounding-surface plasticity model of Shen et al. (1995). Modifications were made to model the effects of residual stress within the steel section. The residual stress at a fiber is modeled explicitly as an initial elastic stress in the uniaxial constitutive relation. The Lehigh residual stress pattern (Galambos and Ketter 1958) is used to define the value of residual stress in the steel section with a maximum compressive residual stress of $30 \%$ of the yield strength occurring at the flange tips. The confined concrete is assumed to prevent flange and web local buckling and thus, these effects have not been included. In contrast, the model by Elnashai and Elghazouli (1993) is for partially encased composite columns and includes flange local buckling since the concrete only prevents inward buckling of the flange. For simplicity, the wide flange steel section is modeled with sharp corners (i.e., neglecting the fillets).

The constitutive relation for the concrete is based on the rule-based model of Chang and Mander (1994). The backbone stress-strain curve for the concrete is based on the model by Tsai, which is defined by the initial stiffness $E_{c}$, peak coordinate $\left(\varepsilon^{\prime}{ }_{\mathrm{cc}}, f^{\prime}{ }_{c c}\right)$, and $r$ which acts as a shape factor. The confinement model developed by Mander et al. (1988) for a triaxial state of stress is utilized to determine the peak compressive 
strength from the confining pressure in two orthogonal directions (Equations 1 through 5).

$$
\begin{gathered}
K=\frac{f_{c c}^{\prime}}{f_{c}^{\prime}}=1+A \bar{x}\left(0.1+\frac{0.9}{1+B \bar{x}}\right) \\
A=6.8886-(0.6069+17.275 r) e^{-4.989 r} \\
B=\frac{4.5}{\frac{5}{A}\left(0.9849-0.6306 e^{-3.8939 r}\right)-0.1}-5 \\
\bar{x}=\frac{f_{l 1}+f_{l 2}}{2 f_{c}} \quad r=\frac{f_{l 1}}{f_{l 2}} \quad f_{l 1} \leq f_{l 2} \\
\varepsilon_{c c}^{\prime}=\varepsilon_{c}(1+5(K-1))
\end{gathered}
$$

where, the strain at peak stress for unconfined concrete, $\varepsilon_{c}$, is given by Equation 6

$$
\varepsilon_{c}=f_{c}^{\prime 0.25} / 1150.0
$$

In order to accommodate low values of $r$ necessary to model high confinement pressures, two values of $r$ are used; one prior to the peak stress reached and one after the peak stress is reached. The value used prior to the peak is based on unconfined concrete, while the one after the peak accounts for the level of confinement and is based on a comparison of the models of Tsai and Popovics (Chang and Mander 1994). These and other parameters for the concrete model are as described in Table 1.

The outermost concrete region of concrete, also termed the cover concrete, is assumed to have zero confining pressure in either direction. Furthermore, it is allowed to spall. Spalling is modeled by modifying the nonlinear compressive backbone curve so that the stress and tangent reduce to and remain at zero after a certain strain. The concrete inside the lateral reinforcing bars is termed the medium confined concrete. In this region, confining pressure is provided by the lateral reinforcing bars. The magnitude of the confining pressure is computed in two orthogonal directions with Equations 7 and 8.

$$
\begin{gathered}
f_{l y, \text { medium }}=K_{e} \rho_{y} F_{y r} \\
f_{l z \text {,medium }}=K_{e} \rho_{z} F_{y r}
\end{gathered}
$$

where, $K_{e}$ is the ratio of effectively confined cross sectional area to area of the core as defined by Mander et al. (1988), $\rho_{y}, \rho_{z}$ are the volumetric ratios of the transverse reinforce steel in either direction as defined by Mander et al. (1988), and $F_{y r}$ is the yield strength of the longitudinal reinforcement.

The concrete between the flanges is termed highly confined concrete. In this region, confining pressure is provided by the lateral reinforcing bars and the steel shape. ElTawil and Deierlein (1999) developed a mechanism model in which the confining pressure provided by the steel shape acts only in the $y$ direction (Figure 1) and is 
computed considering the plastic moment capacity of the flange (Equation 9). The distance between the vertex of the parabola defining the boundary between the highly and medium confined concrete (Figure 1) and the centerline of the steel section is described by Equation 10. This parabolic boundary is modeled explicitly with different constitutive relations on either side. In contrast, the parabolic boundary between the cover and medium confined concrete is implicitly modeled, utilizing the factor $K_{e}$ to provide average behavior. The difference in handling these two boundaries exists to provide greater accuracy in modeling the boundary between the flanges while retaining the flexibility of different possible configurations of reinforcing steel. A comparison of the monotonic compressive response of the concrete in each of the three regions is shown in Figure 2.

$$
\begin{gathered}
f_{l y, \text { high }}=f_{l y, \text { medium }}+\frac{t_{f}^{2} F_{y s}}{0.75\left(b_{f}-t_{w}\right)^{2}} \\
z_{a}=0.50 b_{f}-0.25\left(d-2 t_{f}\right) \geq 0.50 t_{w}
\end{gathered}
$$

The discretization of the fiber section (i.e., computation of location and area of the fibers) is consistent with the geometric description of the cross section presented here. The sum of the area of the fibers for each material type and the total for the section are exact for the selected geometry and do not change with the fiber density. The moment of inertia of the section as computed from the fibers approaches the exact value with increasing fiber density. The discretization is implemented for general three-dimensional analyses as well as for two-dimensional analyses where bending is along either the strong or weak axis. The fiber discretization for two-dimensional analyses takes the form of strips allowing a significant savings in the number of fibers used. The fiber density is defined as the nominal number of fibers along the strong and weak axis with the number of fibers for individual section components (e.g., steel flanges or concrete cover) determined in proportion to their size relative to the entire section. A discretization of $20 \times 20$ (or simply 20 for two dimensional analyses) is found to be both accurate and efficient and is used for the analyses presented in this paper.

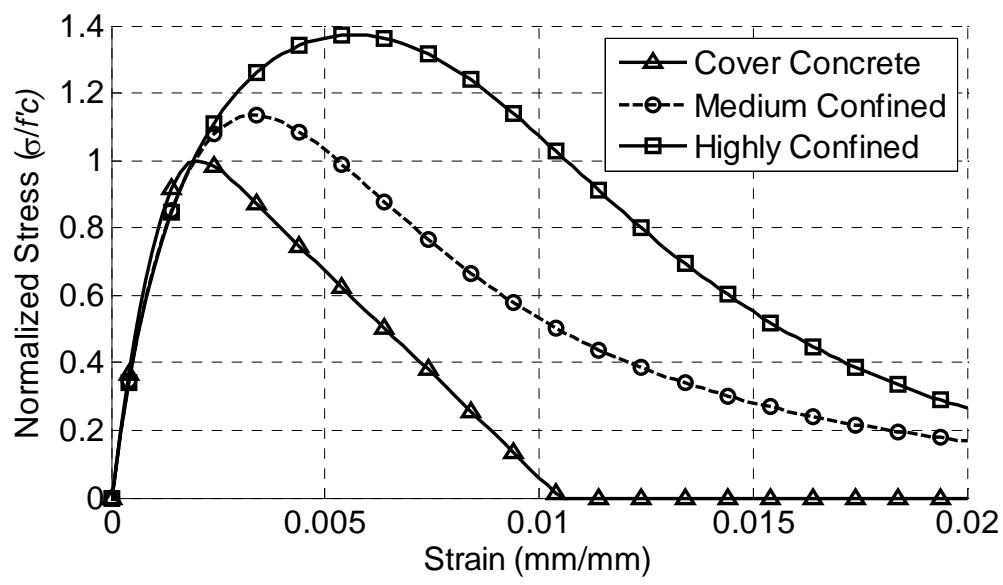

Figure 2. Concrete Constitutive Relations 
Table 1. Concrete Material Properties

\begin{tabular}{|c|c|c|c|c|c|}
\hline & $\begin{array}{c}\text { Highly } \\
\text { Confined }\end{array}$ & $\begin{array}{l}\text { Medium } \\
\text { Confined }\end{array}$ & Cover \\
\hline & Initial Stiffness & $E_{c}$ & $E_{c}[\mathrm{MP}$ & $=12,400+5$ & {$[\mathrm{MPa}]$} \\
\hline \multirow{5}{*}{ 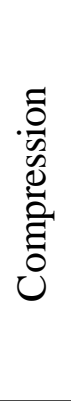 } & \multirow{2}{*}{ Confinement Pressure } & $f_{l y}$ & (Equation 7) & (Equation 9) & 0 \\
\hline & & $f_{l z}$ & \multicolumn{2}{|c|}{ (Equation 8) } & 0 \\
\hline & Peak Stress & $f^{\prime}{ }_{c c}$ & \multicolumn{2}{|c|}{ (Equation 1) } & $f^{\prime}{ }_{c}$ \\
\hline & Strain at Peak Stress & $\varepsilon^{\prime}{ }_{c c}$ & \multicolumn{2}{|c|}{ (Equation 5) } & (Equation 6) \\
\hline & Shape Factor & $\begin{array}{l}r_{\text {pre }} \\
r_{\text {post }}\end{array}$ & \multicolumn{3}{|c|}{$\begin{array}{c}r_{p r e}=f_{c}^{\prime}[\mathrm{MPa}] / 5.2-1.9 \\
r_{p o s t}=E_{c} \varepsilon_{c c} / f_{c c}^{\prime}\end{array}$} \\
\hline \multirow{3}{*}{$\frac{\sigma}{0}$} & Peak Stress & $f^{\prime}{ }_{t}$ & \multirow{3}{*}{\multicolumn{3}{|c|}{$\begin{array}{c}f_{t}[\mathrm{MPa}]=0.5 \sqrt{f_{c}^{\prime}[\mathrm{MPa}]} \\
\varepsilon_{t}=1.23 f_{t} / E_{c} \\
4.0\end{array}$}} \\
\hline & Strain at Peak Stress & $\varepsilon^{\prime}{ }_{t}$ & & & \\
\hline & Shape Factor & $r$ & & & \\
\hline
\end{tabular}

\section{VALIDATION OF THE FINITE ELEMENT METHOD}

To validate the accuracy the model, a large number of comparative analyses were performed against experimental results. A selection of the validation results for monotonic proportionally loaded beam-columns and cyclic non-proportionally loaded beam-columns is presented here.

\section{Proportionally Loaded Beam-Columns}

The most common experimental configuration for testing SRC beam-columns is monotonic proportional loading (Figure 3). Tests of this type have been performed by Virdi and Dowling (1973), Roderick and Loke (1975), Morino et al. (1984) and Wang (1999), and others. Details of four specimens from these experimental studies are presented in Table 2. The results of these experiments are compared to results from analyses conducted using the model presented in this work (Figure 4). When the eccentric of the applied load coincided with one of the principal axes of the column (i.e., strong or weak axis bending), one mid-height lateral deflection is reported. When the applied load induces biaxial bending, two mid-height lateral deflections are reported, one for each of the columns principal axes.

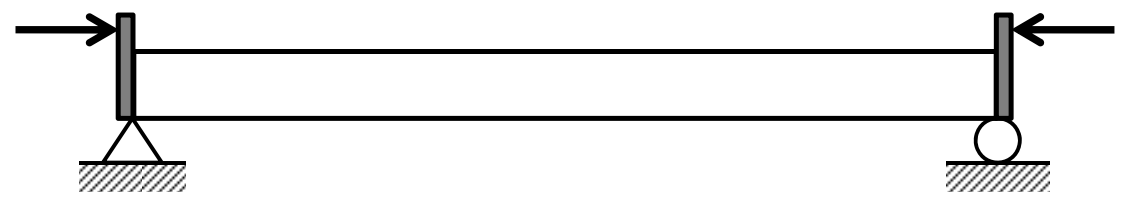

Figure 3. Proportionally Loaded Beam-Column Test Schematic

The results (Figure 4) show a good correlation between experimental and computational results. This is seen in the initial stiffness, peak load, deflection at peak 
load, post-peak degradation, and ratio of strong and weak axis deflections. The two specimens by Morino et al. (1984) (Figure 4c,d) have a similar cross section and loading angle, but specimen D8-45 has approximately twice the length and eccentricity of B4-45. The higher first- and second-order moments resulted in a significantly lower peak axial load for D8-45. The model predicted the peak axial load accurately for both specimens indicating that model captures well both material and geometric nonlinearity.

Table 2. Proportionally Loaded Beam-Column Specimen Data

\begin{tabular}{ccccccccccccc} 
Author & Year & $\begin{array}{c}\text { Spec- } \\
\text { imen }\end{array}$ & $\begin{array}{c}\mathbf{H} \\
\mathbf{( m m})\end{array}$ & $\begin{array}{c}\text { B } \\
\mathbf{( m m})\end{array}$ & $\begin{array}{c}\mathbf{f} \mathbf{c} \\
\mathbf{( M P a})\end{array}$ & Steel Section & $\begin{array}{c}\mathbf{F y} \\
\mathbf{( M P a})\end{array}$ & $\begin{array}{c}\mathbf{d b} \\
\mathbf{( m m})\end{array}$ & $\begin{array}{c}\text { Fyr } \\
(\mathbf{M P a})\end{array}$ & $\begin{array}{c}\text { L } \\
(\mathbf{m m})\end{array}$ & $\begin{array}{c}\text { Axis } \\
\mathbf{( m m})\end{array}$ \\
\hline Wang & 1999 & RSJ1 & 200 & 200 & 55.0 & RSJ 102x102 & 310.0 & n/a & n/a & 4,000 & Strong & 55.0 \\
Virdi and Dowling & 1973 & G & 254 & 254 & 44.8 & UC 6x6@15.7 & 314.7 & 12.7 & 309 & 7,315 & Biaxial & 73.4 \\
Morino et al. & 1984 & B4-45 & 160 & 160 & 23.4 & H-100x100x6x8 & 287.0 & 4.0 & 387 & 2,309 & Biaxial & 40.0 \\
Morino et al. & 1984 & D8-45 & 160 & 160 & 22.9 & H-100x100x6x8 & 302.0 & 4.0 & 387 & 4,619 & Biaxial & 75.0
\end{tabular}

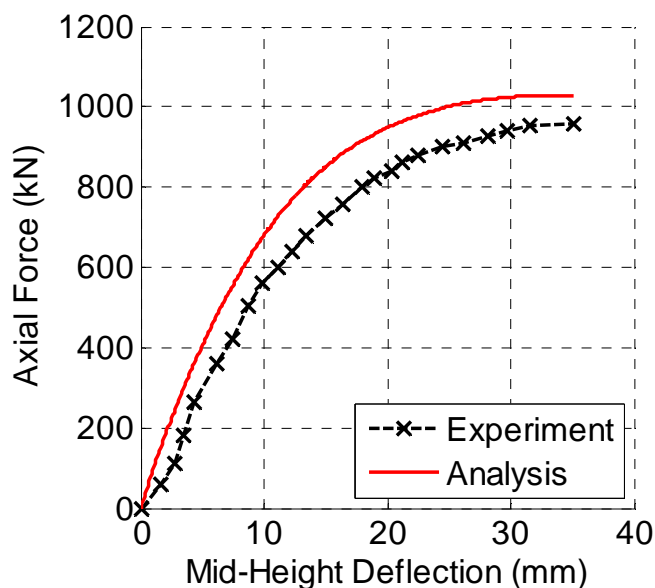

(a) Wang 1999; Specimen: RSJ1

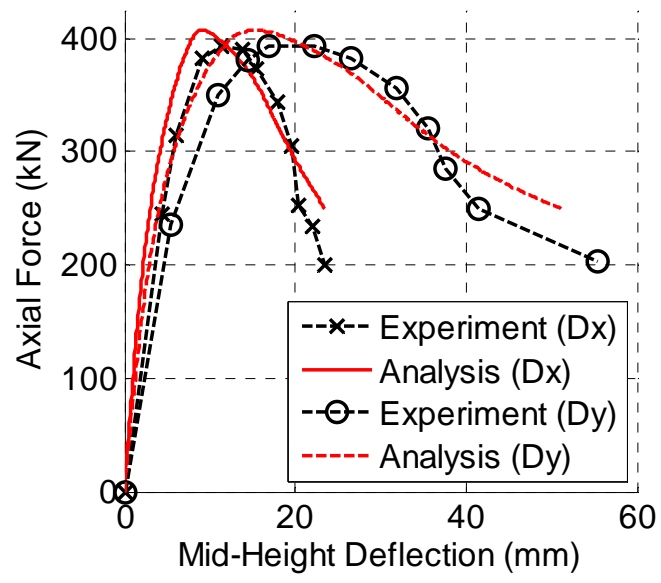

(c) Morino et al. 1984; Specimen B4-45

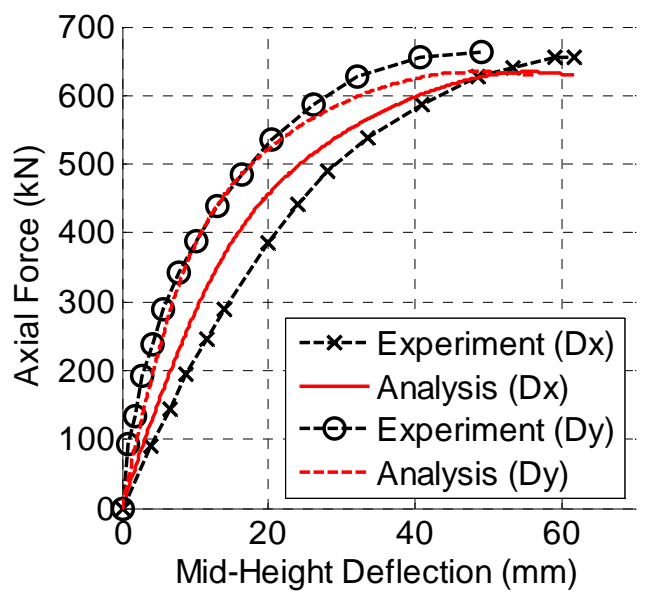

(b) Virdi and Dowling 1973; Specimen G

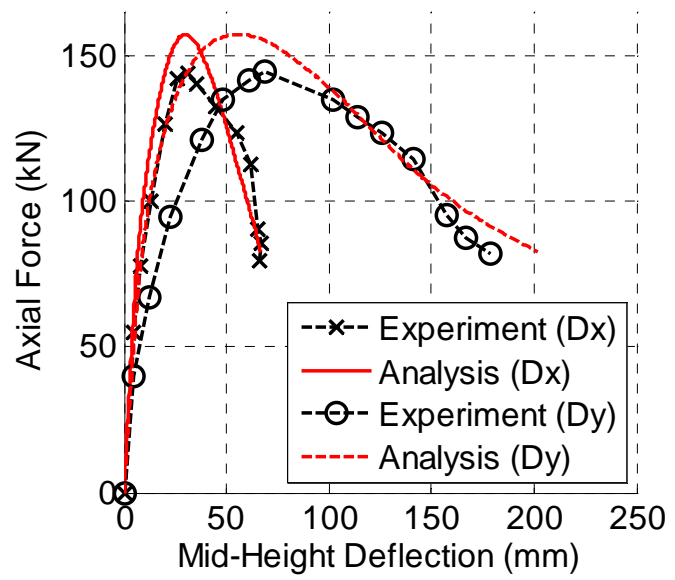

(d) Morino et al. 1984; Specimen D8-45

Figure 4. Proportionally Loaded Beam-Column Validation Results. 


\section{Cyclically Loaded Beam-Columns}

A set of carefully controlled and well documented non-proportionally loaded cyclic SRC beam-columns tests was performed by Ricles and Paboojian $(1993,1994)$. The specimens were subjected to a constant axial load and cyclically increasing horizontal displacements (Figure 5) which induced strong axis bending in the column.

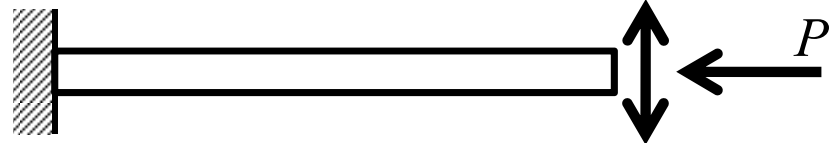

Figure 5. Cyclically Loaded Beam-Column Test Schematic

Details of two of specimens from this experimental study are presented in Table 3. The load-deformation results of these experiments are compared to those from analyses conducted using the model presented in this work (Figure 6a,b). Additionally, the stress-strain response from the extreme fiber of the steel section (Figure 6c) and the extreme fiber of the highly confined concrete (Figure 6d) as predicted from the analysis are shown.

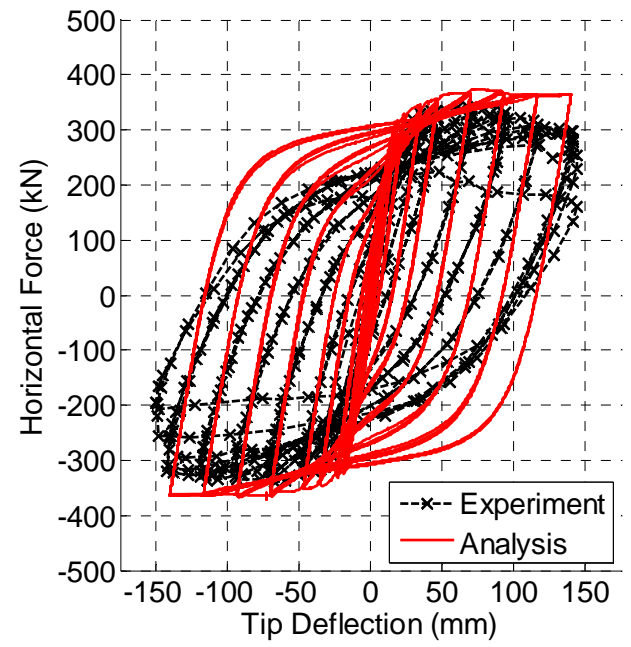

(a) Specimen 6

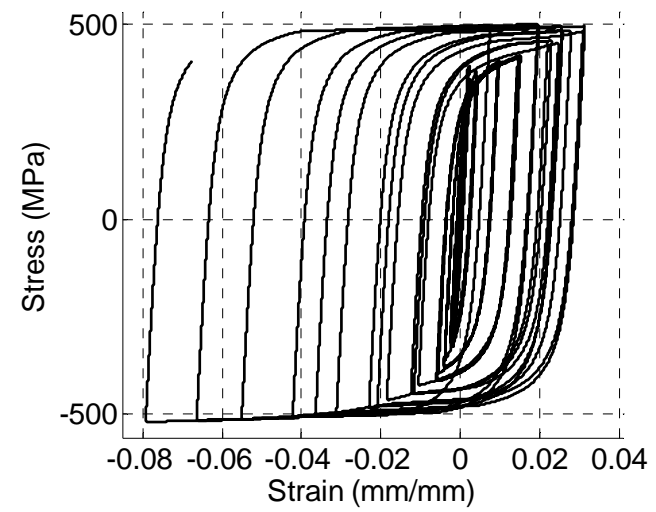

(c) Specimen 6, Steel Section Fiber StressStrain Relationship

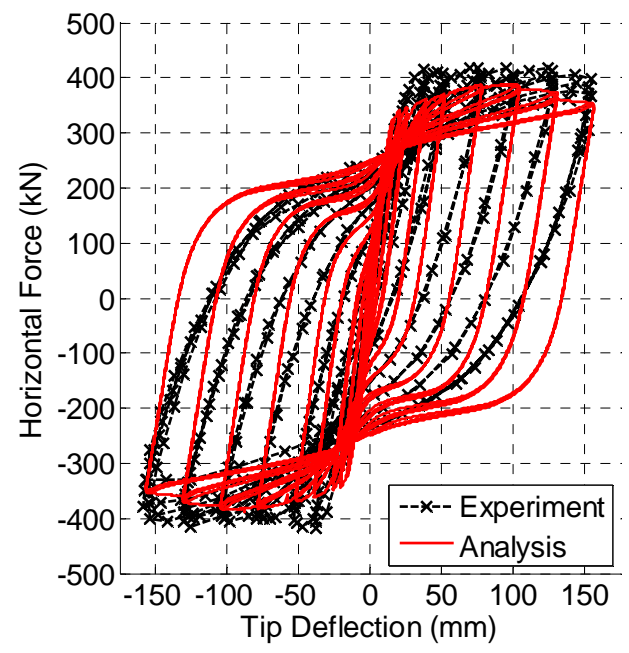

(b) Specimen 8

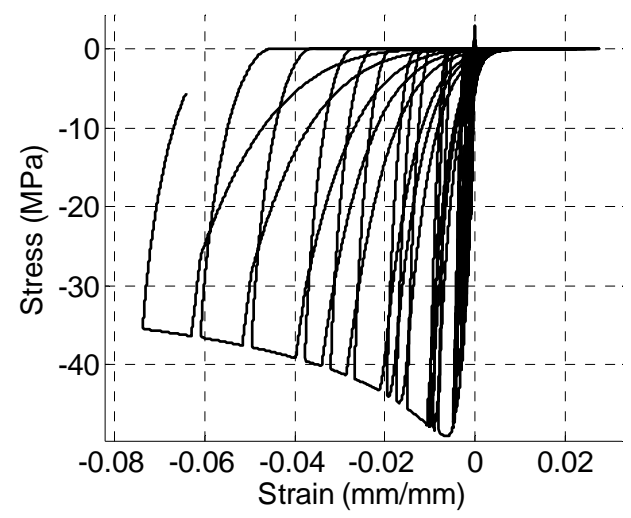

(d) Specimen 6, Highly Confined Concrete Fiber Stress-Strain Relationship

Figure 6. Cyclically Loaded Beam-Column Validation Results. 
Table 3. Cyclically Loaded Beam-Column Specimen Data

\begin{tabular}{cccccccccc}
$\begin{array}{c}\text { Spec- } \\
\text { imen }\end{array}$ & $\begin{array}{c}\mathbf{H} \\
(\mathbf{m m})\end{array}$ & $\begin{array}{c}\mathbf{B} \\
\mathbf{( m m})\end{array}$ & $\begin{array}{c}\mathbf{f}^{\prime} \mathbf{c} \\
(\mathbf{M P a})\end{array}$ & $\begin{array}{c}\text { Steel } \\
\text { Section }\end{array}$ & $\begin{array}{c}\mathbf{F}_{\mathbf{y}} \\
(\mathbf{M P a})\end{array}$ & $\begin{array}{c}\mathbf{d b} \\
(\mathbf{m m})\end{array}$ & $\begin{array}{c}\mathbf{F y r}_{\mathbf{y r}} \\
(\mathbf{M P a})\end{array}$ & $\begin{array}{c}\mathbf{L} \\
(\mathbf{m m})\end{array}$ & $\begin{array}{c}\mathbf{P} \\
\mathbf{k N})\end{array}$ \\
\hline 6 & 406 & 406 & 35.8 & $\mathrm{~W} 8 \times 40$ & 372 & 28.6 & 448 & 1,930 & 1,490 \\
8 & 406 & 406 & 62.9 & $\mathrm{~W} 8 \times 40$ & 372 & 22.2 & 434 & 1,930 & 1,490
\end{tabular}

The results (Figure 6) show a good correlation between experimental and computational results. The initial stiffness and peak strength are predicted well by the model. The unloading stiffness and yield upon unloading are less accurate, leading to the model predicting fuller hysteresis loops than observed in the experiments. Similar discrepancies between experimental and computational results have been noted in other SRC models (e.g., Elnashai and Elghazouli 1993).

\section{CONCLUSION}

A finite element formulation for analysis of SRC members and frames has been presented. The formulation included a mixed based distributed-plasticity beam element and uniaxial constitutive relations. The cyclic uniaxial constitutive relations account for the salient features of SRC behavior. The concrete constitutive relation was based on a rule based model from the literature. Three regions of concrete were defined with separate material properties based on computed levels of confinement pressure. The steel constitutive relation was based on a bounding surface plasticity model from the literature with modifications so that residual stresses could be modeled explicitly within the steel section. A validation was performed showing good correspondence between experimental and computational results for a selection of both monotonic and cyclic tests. The finite element formulation provides an accurate analysis tool for use with composite frames and is suitable for use in parametric studies such as those necessary to develop system behavior factors.

\section{ACKNOWLEDGMENTS}

The authors thank Tiziano Perea for his advice in the completion of this work. The work described here is part of a NEESR project supported by the National Science Foundation under Grant No. CMMI-0619047, the American Institute of Steel Construction, the Georgia Institute of Technology, and the University of Illinois at Urbana-Champaign. Any opinions, findings, and conclusions expressed in this material are those of the authors and do not necessarily reflect the views of the National Science Foundation or other sponsors.

\section{REFERENCES}

Alemdar, B. N. and White, D. W. (2005). "Displacement, Flexibility, and Mixed Beam-Column Finite Element Formulations for Distributed Plasticity Analysis,” Journal of Structural Engineering, ASCE, 131(12), 1811-1819.

Chang, G. A. and Mander, J. B, (1994). "Seismic Energy Based Fatigue Damage Analysis of Bridge Columns: Part I - Evaluation of Seismic Capacity,”

National Center for Earthquake Engineering Research, State University of New York at Buffalo. Department of Civil Engineering, Buffalo, New York.

Chen, C.-C. and Lin, N.-J. (2006). "Analytical Model for Predicting Axial Capacity and Behavior of Concrete Encased Steel Composite Stub Columns,” Journal of Constructional Steel Research, 62(5), 424-433. 
Denavit, M. (2009). "Nonlinear Seismic Analysis of Circular Concrete-Filled Steel Tube Members and Frames,” M.S. Thesis, University of Illinois at UrbanaChampaign, Urbana, Illinois.

Elnashai, A. S. and Elghazouli, A. Y. (1993). "Performance of Composite Steel/Concrete Members under Earthquake Loading. Part I: Analytical model," Earthquake Engineering \& Structural Dynamics, 22(4), 315-345.

El-Tawil, S. and Deierlein, G. G. (2001). "Nonlinear Analysis of Mixed SteelConcrete Frames. II: Implementation and Verification,” Journal of Structural Engineering, ASCE, 127(6), 656-665.

Federal Emergency Management Agency (FEMA). (2009). Quantification of Building Seismic Performance Factors, FEMA P695, Washington, D.C.

Galambos, T. V., and Ketter, R. L. (1958). "Columns under Combined Bending and Thrust.” Journal of the Engineering Mechanics Division, ASCE, 85(2), 135152.

Mander, J. B., Priestley, M. J. N., and Park, R. (1988). “Theoretical Stress-Strain Model for Confined Concrete,” Journal of Structural Engineering, ASCE, 114(8), 1804-1826.

Mirza, S.A. (1989). "Parametric Study of Composite Column Strength Variability," Journal of Constructional Steel Research, 14(2), 121-137.

Morino, S., Matsui, C., and Watanabe, H. (1984). "Strength of Biaxially Loaded SRC Columns,” Composite and Mixed Construction, ASCE, New York, 185-194.

OpenSees (2011). "Open System for Earthquake Engineering Simulation,” Open source software, http://opensees.berkeley.edu.

Ricles, R. and Paboojian S. D. (1993). "Seismic Performance of Composite BeamColumns,” Report No. 93-01, ATLSS Engineering Research Center, Lehigh University, Bethlehem, Pennsylvania.

Ricles, R. and Paboojian S. D. (1994). "Seismic Performance of Steel-Encased Composite Columns,” Journal of Structural Engineering, ASCE, 120(8), 2474-2494.

Roderick, J. W. and Loke, Y. O. (1975). "Pin-Ended Composite Columns Bent About the Minor Axis,” Civil Engineering Transactions, 17(2), 51-58.

Sanz Picon, C. F. (1992). "Behavior of Composite Column Cross Sections under Biaxial Bending” M.S. Thesis, Cornell University, Ithaca, New York.

Shen, C., Mamaghani, I. H. P., Mizuno, E., and Usami, T. (1995). "Cyclic Behavior of Structural Steels. II: Theory,” Journal of Engineering Mechanics, ASCE 121(11), 1165-1172.

Tort, C. and Hajjar, J. F. (2010). “Mixed Finite-Element Modeling of Rectangular Concrete-Filled Steel Tube Members and Frames under Static and Dynamic Loads," Journal of Structural Engineering, ASCE, 136(6), 654-664.

Virdi, K. S. and Dowling, P. J. (1973). "The Ultimate Strength of Composite Columns in Biaxial Bending," Proceedings of the Institute of Civil Engineering (London) 55(2), 251-72.

Wang, Y. C. (1999). “Tests on Slender Composite Columns," Journal of Constructional Steel Research, 49(1), 25-41. 